10 Olive JT Jr, Hyatt RE. Maximal expiratory flow and total respiratory resistance during induced bronchoconstriction in asthmatic subjects. Am Rev Respir Dis 1972; 106: 366-376.

DOI: 10.1183/09031936.06.00142105

\section{From the authors:}

We would like to thank D. Stanescu for giving us the opportunity to clarify the definition of airflow obstruction recently given in the interpretative strategies document from the American Thoracic Society/European Respiratory Society (ERS) Task Force [1]. The document states that in most cases a ratio of forced expiratory volume in one second (FEV1) to vital capacity (VC) below the lower limits of normality is the parameter that best and most frequently embodies the concept of airflow obstruction with few exceptions. However, in some cases, a low FEV1 with a normal FEV1/VC may also be consistent with an obstructive pattern if total lung capacity is normal. This pattern has been observed after exposing the airways to a constrictor agent $[2,3]$ or in natural respiratory diseases [4], reproduced in healthy subjects [5, 6], and has already been interpreted as consistent with airway narrowing in the 1993 ERS guidelines on lung function testing [7]. The fact that this may be caused by a patchy collapse of the small airways on early expiration or expiratory flow limitation that, in turn, would cause an increase in residual volume was suggested by Olive and HyATT [2] in 1972 and then by other investigators in the years that followed $[3,5,6]$. However, this hypothesis still needs confirmation, especially after the demonstration that even the large airways may close with induced bronchoconstriction [8], thus suggesting that the small airways are not the only ones that may contribute towards the generation of air trapping and an increase in residual volume.

As previously mentioned in an editorial [9], the recent papers by STANESCU and co-workers $[10,11]$ merely confirm once again that this pattern exists and must be correctly identified in our daily clinical practice. Yet, neither of the papers bring any evidence that small airways closure is the underlying mechanism, as claimed by the author, thus leaving the field open to further evidence or alternative hypotheses [12]. If we accept that closure or extreme flow limitation are the probable mechanisms for the decrease in forced expiratory volume in one second with normal forced expiratory volume in one second/vital capacity ratio and total lung capacity, then we should also accept that they are the extreme forms of airway narrowing. In this sense, this pattern should be interpreted as obstructive in nature until disproved.
R. Pellegrino*, V. Brusasco", R.O. Crapo ${ }^{\Uparrow}$ and

G. Viegi ${ }^{+}$

*Azienda Ospedaliera S. Croce e Carle, Cuneo, " University of Genoa, Genova, and ${ }^{+}$CNR Institute of Clinical Physiology, Pisa, Italy. ${ }^{\circledR}$ LDS Hospital, Salt Lake City, UT, USA.

\section{REFERENCES}

1 Pellegrino R, Viegi G, Brusasco V, et al. Interpretative strategies for lung function tests. Eur Respir J 2005; 26: 948-968.

2 Olive JT, Hyatt RE. Maximal expiratory flow and total respiratory resistance during induced bronchoconstriction in asthmatic subjects. Am Rev Respir Dis 1972; 106: 366-376.

3 Gibbons WJ, Sharma A, Lougheed D, Macklem PT. Detection of excessive bronchoconstriction in asthma. Am J Respir Crit Care Med 1996; 153: 582-589.

4 Guerry-Force ML, Müller NL, Wright JL, et al. A comparison of bronchitis obliterans with organizing pneumonia, usual interstitial pneumonia, and small airways disease. Am Rev Respir Dis 1987; 135: 705-712.

5 Hyatt RE, Okeson GC, Rodarte JR. Influence of expiratory flow limitation on the pattern of lung emptying in man. J Appl Physiol 1973; 35: 411-419.

6 Rodarte JR, Hyatt RE, Cortese DA. Influence of expiratory flow on closing capacity at low expiratory flow rates. J Appl Physiol 1975; 39: 60-65.

7 Quanjer PH, Tammeling GJ, Cotes JE, Pedersen OF, Peslin R, Yernault JC. Lung volumes and forced ventilatory flows. Report Working Party Standardization of Lung Function Tests, European Community for Steel and Coal. Official Statement of the European Respiratory Society. Eur Respir J 1993; 6: Suppl. 16, 5-40.

8 Pellegrino R, Biggi A, Papaleo A, Camuzzini GF, Rodarte JR, Brusasco V. Regional expiratory flow limitation studied with Technegas in asthma. J Appl Physiol 2001; 91: 2190-2198.

9 Pellegrino R, Brusasco V. Assessing airflow obstruction: when everything is not so obvious. Respiration 2004; 71: 557-558.

10 Stănescu D. Small airways obstruction syndrome. Chest 1999; 116: 231-233.

11 Stănescu D, Veriter C. A normal FEV1/VC ratio does not exclude airway obstruction. Respiration 2004; 71: 348-352.

12 Lambert RK, Wilson TA. Smooth muscle dynamics and maximal expiratory flow in asthma. J Appl Physiol 2005; 99: 1885-1890.

DOI: $10.1183 / 09031936.06 .00015706$

\title{
Inhaler technique blind spot
}

\section{To the Editors:}

The paper by LAFOREST et al. [1] in a recent issue of the European Respiratory Journal is an important reminder of the poor overall management of patients with asthma. A large number of
French patients were studied, but one can assume that similar results would have been found in any country in Europe. The message that this paper clearly sends to all concerned with the management of asthma is that patients under the supervision of specialists do better than those under the care of general 